\title{
Komparasi Hasil Belajar Matematika Siswa yang Diajar dengan Model Pembelajaran Kooperatif Tipe STAD Berbantuan Media Mistar Geser Bilangan Bulat Dan Media Video Mistar Geser Pada Kelas VII SMP
}

\author{
Alfiah Mutmainnah Ali ${ }^{1, a)}$, Alimuddin ${ }^{1,}$ dan Asdar $^{2,}$ \\ ${ }^{1}$ Jurusan Matematika FMIPA Universitas Negeri Makassar \\ a)alfiahmutmainnah0606@gmail.com
}

\begin{abstract}
Abstrak. Penelitian ini dilakukan untuk mengetahui perbandingan hasil belajar siswa melalui penerapan model kooperatif tipe Student Teams Achievement Divitions berbantuan media mistar geser dan video mistar geser dalam pembelajaran matematika. Penelitian ini adalah penelitian eksperimen yang melibatkan dua kelompok yang diberi perlakuan dengan sampel penelitian sebanyak 73 siswa dari kelas VII SMP di Makassar yang dipilih dengan menggunakan teknik double cluster double random sampling. Teknik pengumpulan data menggunakan instrumen: (1) lembar observasi keterlaksanaan model pembelajaran dan (2) tes hasil belajar matematika. Data dianalisis dengan statistik deskriptif dan statistik inferensial dengan analisis uji-t. Hasil penelitian menunjukkan bahwa : (1) Skor rara-rata hasil belajar matematika dari 37 siswa setelah pembelajaran menggunakan model pembelajaran kooperatif tipe Student Teams Achievement Divitions berbantuan media mistar geser yaitu 22,22\% berada pada kategori sangat rendah, 22,22\% pada kategori sedang, 13,90\% pada kategori tinggi dan 19,44\% pada kategori sangat tinggi. (2) Skor rara-rata hasil belajar matematika dari 36 siswa setelah pembelajaran menggunakan model pembelajaran kooperatif tipe Student Teams Achievement Divitions berbantuan media video mistar geser yaitu $18,92 \%$ berada pada kategori sangat rendah, 24,32\% pada kategori rendah, 40,54\% pada kategori sedang serta 13,52\% pada kategori tinggi dan 2,70 pada kategori sangat tinggi. (3) Tidak terdapat perbedaan yang signifikan antara hasil belajar siswa setelah menerapkan model pembelajaran kooperatif tipe Student Teams Achievement Divitions berbantuan media mistar geser dan video mistar geser di Kelas VII SMP dengan materi Penjumlahan dan Pengurangan Bilangan Bulat. Kata Kunci: Hasil belajar, pembelajaran matematika, model pembelajaran kooperatif, Student Teams Achievement Divitions
\end{abstract}

\begin{abstract}
This research was conducted to determine the comparison of student learning outcomes through the application of the cooperative model type Student Teams Achievement Divitions assisted by slide rule media and Student Teams Achievement Divitions assisted by slide bar video media. This research was an experimental research involving two groups treated with research sample of 73 students from class VII SMP Sinjaiselected by using the double cluster random sampling technique. Techniques of collecting data using instruments: (1) observation sheet of learning model implementation and (2) tests of mathematics learning result.Data were analyzed with descriptive statistics and inferential statistics with t-test analysis. The results showed that : (1) Average score of mathematics learning outcomes of 37 students after learning using the Student Teams Achievement Divitions assisted by slide rule media model which is $22,22 \%$ in the very low category, 22,22\% in the medium category, $13,90 \%$ in the high category and $19,44 \%$ in the very high category. (2) The average score of mathematics learning outcomes from 36 students after learning using the Teams Achievement Divitions assisted by slide bar video media is $18,92 \%$ in the very low category, $24,32 \%$ in the low category, $40,54 \%$ in the medium category $13,52 \%$ in the high and 2,70\% very high categories. (3) There is no significant difference between student learning outcomes after applying the Student Teams Achievement Divitions assisted by slide rule media and Student Teams Achievement Divitions assisted by slide bar video media. in Class VII Junior High School with the material of Addition and Subtraction Round Numbers.
\end{abstract}

Keywords:Learning outcomes, mathematics learning, cooperative learning model, student teams achievement divitions 


\section{PENDAHULUAN}

Dalam upaya meningkatkan hasil belajar matematika siswa, maka guru harus pandai memilih dan menerapkan model pembelajaran yang tepat. Model pembelajaran adalah serangkaian penyajian materi ajar yang dilakukan oleh guru didalam proses pembelajaran. Salah satu model pembelajaran yang dapat diterapkan didalam proses pembelajaran yaitu model Pembelajaran Kooperatif. Pembelajaran kooperatif merupakan sistem pengajaran yang memberikan kesempatan kepada anak didik untuk bekerja sama. Pembelajaran kooperatif dikenal dengan pembelajaran secara kelompok. Tetapi belajar kooperatif lebih dari sekedar belajar kelompok atau kerja kelompok, karena dalam belajar kooperatif ada struktur dorongan atau tugas yang bersifat kooperatif sehingga memungkinkan terjadinya interaksi secara terbuka.

Tipe Student Teams Achievement Divitions (STAD) merupakan salah satu tipe dari model pembelajaran kooperatif yang menekankan pada prestasi tim berasarkan rekognisi tim yang diperoleh dari jumlah seluruh skor kemajuan individual setiap anggota tim. Dalam pembelajaran ini, siswa dikelompokkan menjadi beberapa tim yang terdiri atas 4-5 siswa yang mewakili seluruh bagian dari kelas dalam hal kinerja akademik, jenis kelamin, ras, dan etnisitas. (Eka, 2015). Sebelum memulai pembelajran kooperatif tipe STAD, siswa dikelompokkan dalam kelompok-kelompok kecil. Pembentukan kelompok-kelompok tersebut dilakukan oleh guru berdasarkan pertimbangan tertentu, dan mengoptimalkan manfaat pembelajaran kooperatif tipe STAD, keanggotaannya sebaiknya heterogen. (Husnah, 2016). Beberapa penelitian telah mengkaji tentang tipe STAD (Marheni, 2013; Sunilawati, 2013; Marsih, 2013). Penelitian tersebut mengemukakan bahwa penerapan tipe STAD dapat meningkatkan hasil belajar matematika siswa.

Pada pembelajaran guru sabaiknya menggunakan media belajar, media tidak harus berteknologi tinggi dan dibeli dengan harga yang mahal, tapi dapat menggunakan media belajar yang sederhana, murah serta dapat dibuat oleh guru itu sendiri. Gerlach \& Ely (1971) mengantakan bahwa media apabila dipahami secara garis besar adalah manusia, materi, atau kejadian yang membangun kondisi yang membuat siswa mampu memperoleh peraturan, keterampilan, atau sikap. Secara lebih khusus, pengertian media dalam proses belajar mengajar cenderung diartikan sebagai alat grafis, photografis, atau elektronis untuk menangkap, memproses, dan menyusun kembali informasi visual atau verbal. Adapun media pembelajaran yang dapat diterapkan yaitu mistar geser dan video mistar geser.

Mistar geser adalah alat bantu untuk menghitung penjumlahan dan pengurangan pada bilangan bulat yang dapat dibuat sendiri dari kayu serta digunakan untuk membantu siswa dalam proses pembelajaran dan mudah dipahami oleh siswa. Beberapa penelitian telah mengakaji terkait media mistar hitung (Surojo, 2013; Saman, 2014). Penelitian tersebut menunjukkan bahwa pembelajaran matematika berbantuan media mistar hitung dapat meningkatkan hasil belajar. Sedangkan Media video mistar geser adalah alat peraga yang digunakan dalam proses belajar yang dinikmati lewat panca indera. Adapun peneliti telah mengkaji terkait video mistar hitung (Saeun, 2017). Penelitian tersebut menunjukkan bahwa pembelajaran matematika berbantuan media video mistar hitung dapat meningkatkan hasil belajar.

Pada penelitian ini mengkaji tentang komparasi hasil belajar matematika siswa yang diajar dengan model pembelajaran kooperatif tipe STAD berbantuan media mistar geser dan video mistar geser pada kelas VII SMP. 


\section{KAJIAN PUSTAKA}

\section{Pembelajaran Kooperatif}

Pembelajaran kooperatif merupakan sistem pengajaran yang memberikan kesempatan kepada anak didik untuk bekerja sama dengan sesama siswa dalam tugas-tugas yang terstruktur. Pembelajaran kooperatif dikenal dengan pembelajaran secara kelompok. Tetapi belajar kooperatif lebih dari sekedar belajar kelompok atau kerja kelompok karena dalam belajar kooperatif ada struktur dorongan atau tugas yang bersifat kooperatif sehingga memungkinkan terjadinya interaksi secara terbuka dan hubungan yang bersifat interdepensi efektif diantara anggota kelompok. Menurut Trianto (2009) menyatakan bahwa dalam belajar kooperatif siswa belajar bersama sebagai suatu tim dalam menyelesaikan tugas-tugas kelompok untuk mencapai tujuan bersama. Jadi, setiap anggota kelompok memiliki tanggung jawab yang sama untuk keberhasilan kelompoknya. Menurut Trianto (2009) Terdapat lima unsur dalam pembelajran kooperatif yaitu: (a) Saling ketergantungan yang bersifat positif antara siswa; (b) Interaksi antara siswa yang semakin meningkat; (c) Tanggung jawab individual; (d) Keterampilan interpersonal dan kelompok kecil; (e) Proses kelompok. Menurut Jalali (2015) bahwa pembelajaran kooperatif dengan enam tahap yang harus dilakukan dalam melaksanakan pembelajaran yaitu (1) Menyampaikan tujuan dan memotivasi siswa; (2) Penyajian Informasi; (3) Mengorganisasikan siswa kedalam kelompok-kelompok belajar; (4) Membimbing kelompok belajar; (5) Evaluasi; (6) Memberikan penghargaan.

\section{STAD}

STAD merupakan salah satu tipe dari model pembelajaran kooperatif yang menekankan pada prestasi tim berasarkan rekognisi tim yang diperoleh dari jumlah seluruh skor kemajuan individual setiap anggota tim. Dalam pembelajaran ini, siswa dikelompokkan menjadi beberapa tim yang terdiri atas 4-5 siswa yang mewakili seluruh bagian dari kelas dalam hal kinerja akademik, jenis kelamin, ras, dan etnisitas. Eka (2015). Sebelum memulai pembelajran kooperatif tipe STAD, siswa dikelompokkan dalam kelompok-kelompok kecil. Pembentukan kelompok-kelompok tersebut dilakukan oleh guru berdasarkan pertimbangan tertentu, dan mengoptimalkan manfaat pembelajaran kooperatif, keanggotaannya sebaiknya heterogen, Husnah (2016). Menurut Abidin (2013), jumlah siswa yang bekerja dalam kelompok harus dibatasi, agar kelompok yang terbentuk menjadi efektif, karena ukuran kelompoknya. Ukuran kelompok yang ideal untuk pembelajaran kooperatif tipe STAD adalah empat sampai lima orang. Tabel 1 menunjukkan langkah-langkah pembelajaran kooperatif tipe STAD.

\section{Media Pembelajaran}

Kata media berasal dari bahasa latin medius yang secara harfiah berarti 'tengah', 'perantara' atau 'pengantar'. Dalam bahasa Arab, media adalah perantara atau pengantar pesan dari pengirim kepada penerima pesan. Gerlach \& Ely (1971) mengantakan bahwa media apabila dipahami secara garis besar adalah manusia, materi, atau kejadian yang membangun kondisi yang membuat siswa mampu memperoleh peraturan, keterampilan, atau sikap. Dalam pengertian ini, guru, buku teks, dan lingkungan sekolah merupakan media. Secara lebih khusus, pengertian media dalam proses belajar mengajar cenderung diartikan sebagai alatalat grafis, photografis, atau elektronis untuk menangkap, memproses, dan menyusun kembali informasi visual atau verbal. Pelaksanaan kegiatan belajar mengajar, khususnya kegiatan mengajar yang akan dilakukan oleh guru sangat ditentukan oleh metedeologi pengajaran yang berkaitan dengan metode dan teknik yang akan digunakan oleh guru dalam melakukan interaksinya dengan siswa agar bahan pengajaran sampai kepada siswa. Metode pengajaran terdiri dari dua aspek yaitu metode pengajaran dan media pengajaran. Kesimpulannya Media Pembelajaran adalah segala sesuatu yang dapat digunakan untuk menyampaikan pesan atau informasi dalam proses belajar 
mengajar sehingga dapat merangsang perhatian dan minat siswa dalam belajar. Adapun media pembelajaran yang akan digunakan pada penelitian ini yaitu mistar hitung dan video mistar hitung.

TABEL 1. Langkah-langkah pembelajaran kooperatif tipe STAD

\begin{tabular}{ll}
\hline Fase & \multicolumn{1}{c}{ Deskripsi } \\
\hline Prestasi Kelas & $\begin{array}{l}\text { Prestasi kelas merupakan tahapan dimana guru menyampaikan materi secara } \\
\text { langsung kepada siswa. }\end{array}$
\end{tabular}

Tim Pembentukan tim berdasarkan pada prestasi akademis siswa dalam kelas. Fungsi utama dari tim ini adalah untuk memastikan bahwa semua anggota tim benar-benar belajar, dan lebih khususnya lagi untuk mempersiapkan setiap anggota tim agar dapat mengerjakan kuis dengan baik.

Kuis Pengerjaan soal kuis dilakukan secara individual. Para siswa tidak diperbolehkan untuk saling membantu dalam mengerjakan kuis. Sehingga, tiap siswa bertanggung jawab secara individual untuk memahami materinya.

Skor Setiap siswa diberikan skor awal yang diperoleh dari ratarata kinerja siswa Kemajuan tersebut sebelum mengerjakan kuis. Selanjutnya, siswa akan mengumpulkan Individual poin untuk tim masing-masing berdasarkan tingkat kenaikan skor kuis yang dibandingkan dengan skor awal. Dengan demikian, setiap siswa dapat memberikan kontribusi poin yang maksimal kepada timnya. Perhitungan skor perkembangan individual tersebut dimaksudkan agar siswa termotivasi untuk memperoleh prestasi terbaik sesuai dengan kemampuannya.

Rekognisi $\quad$ Rekognisi tim diperoleh dari rata-rata jumlah seluruh skor perkembangan Tim individu anggota tim. Tim akan mendapatkan sertifikat atau bentuk penghargaan lainnya jika skor rata-rata tim mencapai krikteria tertentu.

\section{Media Pembelajaran}

Kata media berasal dari bahasa latin medius yang secara harfiah berarti 'tengah', 'perantara' atau 'pengantar'. Dalam bahasa Arab, media adalah perantara atau pengantar pesan dari pengirim kepada penerima pesan. Gerlach \& Ely (1971) mengantakan bahwa media apabila dipahami secara garis besar adalah manusia, materi, atau kejadian yang membangun kondisi yang membuat siswa mampu memperoleh peraturan, keterampilan, atau sikap. Dalam pengertian ini, guru, buku teks, dan lingkungan sekolah merupakan media. Secara lebih khusus, pengertian media dalam proses belajar mengajar cenderung diartikan sebagai alatalat grafis, photografis, atau elektronis untuk menangkap, memproses, dan menyusun kembali informasi visual atau verbal. Pelaksanaan kegiatan belajar mengajar, khususnya kegiatan mengajar yang akan dilakukan oleh guru sangat ditentukan oleh metedeologi pengajaran yang berkaitan dengan metode dan teknik yang akan digunakan oleh guru dalam melakukan interaksinya dengan siswa agar bahan pengajaran sampai kepada siswa. Metode pengajaran terdiri dari dua aspek yaitu metode pengajaran dan media pengajaran. Kesimpulannya Media Pembelajaran adalah segala sesuatu yang dapat digunakan untuk menyampaikan pesan atau informasi dalam proses belajar mengajar sehingga dapat merangsang perhatian dan minat siswa dalam belajar. Adapun media pembelajaran yang akan digunakan pada penelitian ini yaitu mistar hitung dan video mistar hitung.

Mistar geser adalah alat bantu untuk menghitung penjumlahan dan pengurangan pada bilangan bulat yang dapat dibuat sendiri dari kayu serta digunakan untuk membantu siswa dalam proses pembelajaran dan mudah dipahami oleh siswa. Mistar hitung yang akan digunakan terdiri dari skala yang sama dan terdiri dari bilangan bulat, yaitu bilangan bulat negatif, nol dan bilangan bulat positif. Mistar geser juga merupakan suatu media atau alat peraga yang menarik dan 
mampu menjadi salah satu solusi untuk meningkatkan aktivitas guru dan siswa dalam pembelajaran operasi hitung dasar bilangan bulat.

Beberapa penelitian telah mengkaji terekait media mistar hitung (Surojo, 2013; Saman,2014). Surojo (2013) meneliti tentang pemanfaatan media mistar hitung untuk memperoleh hasil belajar bilangan bulat di kelas VII. Penelitian ini menunjukan bahwa pembelajaran bilangan bulat dengan menngunakan mistar hitung dapat meningkatkan hasil belajar siswa yang mempunyai kemampuan sedang dan rendah. Selain itu, Saman (2014) meneliti tentang penggunaan alat peraga penggaris geser untuk meningkatkan hasil belajar siswa dalam pembelajaran matematika. Penelitian ini menunjukkan bahwa Hasil belajar Siswa dengan menggunakan alat peraga penggaris geser pada materi penjumlahan dan pengurangan bilangan bulat dalam pembelajaran matematika, Terjadi peningkatan sebesar 14,12 pada siklus I ke siklus ke II, dan 13,58 pada siklus II ke siklus ke III. Hal ini menunjukkan bahwa alat peraga penggaris geser dapat meningkatkan hasil belajar matematika siswa.

Media video mistar geser adalah alat peraga yang digunakan dalam proses belajar yang dinikmati lewat panca indera. Media video ini dapat memperlancar pemahaman dan memperkuat ingatan siswa. Video dapat pula menumbuhkan minat peserta didik. Media video mistar geser yang digunakan sama dengan mistar geser cuman bedanya ini berbentuk video yang hanya bisa di simak oleh peserta didik lain halnya dengan mistar geser siswa bisa mempraktikkan langsung.

Adapun penelitian telah mengkaji tentang video mistar hitung. Saeun (2017) meneliti tentang pemanfaatan media video mistar hitung dan mistar hitung dalam pembelajaran tematik untuk memperoleh hasil belajar matematika siswa. Perolehan hasil belajar dengan menggunakan media video mistar hitung dan mistar hitung, kesulitan pemahaman pebelajar dalam operasi bilangan bulat dapat diatasi. Hal ini dibuktikan dengan nilai perolehan hasil belajar serta ketuntasan pembelajar sebelum diberi perlakuan dan setelah diberi perlakuan penggunaan media. Maka dengan demikian perolehan hasil belajar matematika dengan menggunakan media video mistar hitung dan mistar hitung mempunyai pengaruh yang sangat signifikan.

\section{METODE PENELITIAN}

Penelitian ini merupakan penelitian kuantitatif experiment. Penelitian ini dilaksanakan disalah satu SMP Negeri di Kota Makassar. Sampel dalam penelitian ini adalah dua kelas eksperimen dimana kelas eksperimen I terdiri dari 37 siswa dan diterapkan Model pembelajaran kooperatif tipe STAD berbantuan media mistar geser. Sedangkan kelas eksperimen II terdiri dari 36 siswa dan diterapkan pembelajaran kooperatif tipe STAD berbantuan media video mistar geser.

Instrumen yang digunakan yaitu lembar observasi keterlaksanaan pembelajaran dan tes hasil belajar siswa. Adapun kategori keterlaksanaan proses pembelajaran dan kategori skor tes hasil belajar dapat dilihat pada Tabel 2 dan Tabel 3 .

TABEL 2.Kategori Keterlaksanaan Model Pembelajaran

\begin{tabular}{cc}
\hline Skor Rata-Rata & Kategori \\
\hline $3,5 \leq R \leq 4$ & Sangat Baik \\
$2,5 \leq R<3,5$ & Baik \\
$1,5 \leq R<2,5$ & Cukup Baik \\
$1 \leq \mathrm{R} \leq 1,5$ & Kurang Baik \\
\hline
\end{tabular}

Hipotesis dalam penelitian ini yaitu: $H_{0}: \mu_{1}=\mu_{2}$ lawan $H_{1}: \mu_{1} \neq \mu_{2}$, dimana $\mu_{1}$ adalah parameter rata-rata skor hasil belajar matematika siswa yang diajar menggunakan model pembelajaran kooperatif tipe STAD dengan media mistar geser sedangkan $\mu_{2}$ adalah parameter rata-rata skor 
hasil belajar matematika siswa yang diajar menggunakan model pembelajaran kooperatif tipe STAD dengan video media mistar geser.

Adapun teknik analisis dalam penelitian iniadalah analisis Statistik Deskriptif dan Inferensial. Hasil analisis deskriptif meliputi penyajian data melalui tabel, mean, modus, standar deviasi dan perhitungan persentase. Analisis statistik inferensial menggunakan untuk uji hipotesis penelitian. Metode analisis yang digunakan dalam penelitian ini adalah analisis kuantitatif pada taraf kepercayaan $95 \%(\alpha=0,05)$.

TABEL 3.Kategori Skor Tes Hasil Belajar

\begin{tabular}{cc}
\hline Interval Nilai & Kategori \\
\hline $90-100$ & Sangat Tinggi \\
$80-89$ & Tinggi \\
$65-79$ & Sedang \\
$55-64$ & Rendah \\
$0-54$ & Sangat Rendah \\
\hline
\end{tabular}

\section{HASIL DAN PEMBAHASAN}

Data yang diperoleh dalam penelitian ini adalah data tentang hasil belajar matematika siswa. Hasil perhitungan terhadap hasil belajar matematika siswa pada kelas yang diterapkan model pembelajaran kooperatif tipe STAD berbantuan media mistar hitung dan video mistar hitung.

TABEL 4. Rekapitulasi Hasil Observasi Keterlaksanaan

\begin{tabular}{ccc}
\hline Keterlaksanaan Model & $\begin{array}{c}\text { Skor } \\
\text { rata-rata }\end{array}$ & Klasifikasi \\
\hline mistar geser & 3,89 & Terlaksana dengan Sangat Baik \\
video mistar geser & 3,71 & Terlaksana dengan Sangat Baik \\
\hline
\end{tabular}

Tabel 4 memperlihatkan bahwa hasil observasi keterlaksanaan model pembelajaran kooperatif tipe STAD berbantuan media mistar geser dan pembelajaran kooperatif tipe STAD berbantuan media video mistar geser terlaksana dengan baik. Adapun selisih rata-rata keterlaksanaan kedua model tersebut hanya 0,18 yang mengindikasikan bahwa keterlaksanaan kedua model dianggap sama sehingga layak dibandingkan.

TABEL 5.Rekapitulasi Skor Tes Hasil Belajar Siswa

\begin{tabular}{ccc}
\hline Keterlaksanaan Model & Skor rata-rata & Kategori \\
\hline mistar geser & 68,45 & Sedang \\
video mistar geser & 67,66 & Sedang \\
\hline
\end{tabular}

Tabel 5 memperlihatkan bahwa rata-rata skor hasil belajar matematika pada model pembelajaran kooperatif tipe STAD berbantuan media mistar geser dan pembelajaran kooperatif tipe STAD berbantuan media video mistar geser masing-masing berada pada kategori tinggi dan sedang.Perbedaan nilai rata-rata pada kedua tipe model pembelajaran kooperatif tersebut menunjukkan bahwa terdapat perbedaan antara Hasil belajar siswa pada model kooperatif tipe STAD berbantuan media mistar geser dan pembelajaran kooperatif tipe STAD berbantuan media video mistar geser. Setelah melihat hasil perbandingan kedua model, dapat dikatakan bahwa model kooperatif tipe STAD berbantuan media mistar geser lebih baik dibandingkan tipe STAD berbantuan media video mistar geser 


\section{Uji Normalitas}

Uji normalitas dimaksudkan untuk menguji apakah data yang diperoleh berasal dari populasi yang berdistribusi normal atau tidak. Statistik uji yang digunakan dalam uji normalitas adalah Kolmogorov-Smirnov menggunakan software SPSS. Pengujian dilakukan pada taraf signifikansi $\alpha=5 \%$ atau $\alpha=0,05$.

TABEL 6. Hasil output Uji Normalitas

\begin{tabular}{ccc}
\hline Model Pembelajaran & Nilai Signifikan & Klasifikasi \\
\hline mistar geser & 0,200 & Berdistibusi Normal \\
video mistar geser & 0,200 & Berdistribusi Normal \\
\hline
\end{tabular}

Tabel 6 memperlihatkan hasil output uji normalitas varians dengan menggunakan uji Kolmogorov-Smirnov, menunjukkan nilai signifikan untuk kedua tipe model pembelajaran kooperatif tersebut lebih dari 0,05, maka dapat dikatakan bahwa model pembelajaran kooperatif tipe STAD berbantuan media mistar geser dan tipe STAD berbantuan media video mistar geser berdistribusi normal.

\section{Uji Homogenitas}

Uji homogenitas dimaksudkan untuk menguji apakah data yang diperoleh berasal dari populasi yang homogen atau tidak. Statistik uji yang digunakan dalam uji homogenitas adalah Levene's Test for Quality of Variances menggunakan software SPSS. Pengujian dilakukan pada taraf signifikansi $\alpha=5 \%$ atau $\alpha=0,05$.

TABEL 7. Hasil output Uji Homogenitas

\begin{tabular}{ccccc}
\hline Data & P-value & $\boldsymbol{\alpha}$ & Keputusan & Keterangan \\
\hline postest & 0,717 & 0,05 & P-value $>0.05$ & Homogen \\
\hline
\end{tabular}

Tabel 7 memperlihatkan hasil output uji homogenitas dengan menggunakan SPSS menunjukkan nilai signifikan untuk data posttest adalah 0,717 . Karena nilai signifikansi kedua kelas lebih dari 0,05, maka dapat dikatakan bahwa variansi kelas data sama.

\section{Uji Hipotesis}

Uji hipotesis yang dilakukan dengan uji-t melalui program SPSS 20.0 menggunakan Independent Sample Test dengan asumsi kedua varians normal dan taraf signifikan 0,05.

TABEL 8. Hasil output Uji Hipotesis

\begin{tabular}{ccccc}
\hline Data & P-value & $\boldsymbol{\alpha}$ & Keputusan & Keterangan \\
\hline postest & 0,037 & 0,05 & P-value $>0.05$ & $\mathrm{H}_{0}$ ditolak \\
\hline
\end{tabular}

Table 8 memperlihatkan hasil uji hipotesis yang dilakukan dengan uji-t melalui program SPSS 20.0 menggunakan Independent Sample Test dengan asumsi kedua varians normal dan taraf signifikan 0,05, diperoleh nilai sig.(2-tailed) adalah 0,037>0,05. Dengan demikian dapat disimpulkan bahwa $\mathrm{H}_{0}$ ditolak. Dengan kata lain, peningkatan Hasil belajar penerapan pembelajaran matematika dengan model kooperatif STAD berbantuan media mistar geser memiliki perbedaan dengan STAD berbantuan media video mistar geser dalam mengajarkan materi Penjumlahan dan pengurangan bilangan bulat dikelas VII SMP. 


\section{KESIMPULAN}

Penelitian ini bertujuan untuk mengetahui komparasi hasil belajar matematika siswa dalam penerapan model pembelajaran kooperatif tipe STAD berbantuan media mistar hitung dan video mistar hitung pada kelas VII . Kesimpulan yang diperoleh yaitu terdapat perbedaan hasil belajar matematika siswa pada penerapan model kooperatif tipe STAD berbantuan media mistar geser dan video mistar geser. Pembelajaran dengan berbantuan media mistar hitung lebih baik dari pada berbantuan video mistar hitung.

Dalam penelitian ini hanya membandingkan hasil belajar matematika siswa saja. Terdapat beberapa hal lain yang dapat diteliti terkait tipe STAD berbantuan media. Hal lain yang dapat diteliti diantaranya penerapan Model Pembelajaran Kooperatif tipe STAD berbantuan media mistar geser dan tipe STAD berbantuan media video mistar geser ditinjau dari motivasi, minat belajar siswa atau hal-hal menarik lainnya.

\section{DAFTAR PUSTAKA}

Abidin. (2013). Desain Pembelajaran dalam Konteks Kurikulum 2013.

Eka. (2015). Penelitian Pendidikan Matematika. Bandung : Refika Aditama.

Gerlach \& Ely. (1971). Teaching and media : A systematic approach, Prentice-Hall, Englewood Cliffs, N.J

Husnah, A. (2016). Komparasi Keefektifan Model Kooperatif Tipe Student Teams Achievement Division (STAD) dan Think Pair Share (TPS) dengan Pendekatan Saintifik pada Pembelajaran Matematika Materi Trigonometri di Kelas XI SMAN 1 Bontomatene. (Skripsi). Universitas Negeri Makassar.

Israwati, Tri, 2017. Pengaruh Model Pembelajaran Investigasi Kelompok dengan Pendekatan Scientific Terhadap Motivasi dan Hasil Belajar Matematika Siswa Kelas VIII SMP NEGERI 2 MAPPAKASUNGGU KABUPATEN TAKALAR. Skripsi. FMIPA. Universitas Negeri Makassar

Jalali. Z.W. (2015). Pengaruh. Model Pembelajaran Kooperatif Terhadap Hasil Belajar Matematika. (Skripsi). Universitas Negeri Makassar.

Marhaeni. (2013). Penerapan Model Pembelajaran Kooperatif Tipe STAD untuk Meningkatkan Keaktifan dan Hasil Belajar Siswa. Jurnal PGSD Universitas Pendidikan Ganesha.

Marsih. (2013). Model Pembelajaran Kooperatif Tipe STAD Untuk Meningkatkan Hasil Belajar Matematika Tentang Soal Cerita Pecahan pada Siswa kelas V Sekolah Dasar. Jurnal PGSD Universitas Sebelas Maret.

Purwanto. 2014. Evaluasi Hasil Belajar. Yogyakarta: Pustaka Pelajar.

Saeun. (2017). Pemanfaatan Media video dan Mistar Hitung dalam Pembelajaran Tematik untuk Perolehan Hasil Belajar Matematika di SD. (Tesis). Program Pascasarjana Teknologi Pembelajaran FKIP Untan Pontianak.

Saman. (2014). Penggunaan Alat Peraga Penggaris Geser untuk Meningkatkan Hasil Belajar Siswa dalam Pembelajaran Matematika Kelas V. (Skripsi). Universitas Tanjungpura Pontianak.

Sunilawati. (2013). Pengaruh Model Pembelajaran Kooperatif Tipe STAD Terhadap Hasil Belajar Matematika Ditinjau dari Kemampuan Numerik Siswa. Jurnal PGSD Universitas Pendidikan Ganesha.

Surojo. (2013). Pemanfaatan Media Mistar Hitung untuk Pemerolehan Hasil Belajar Bilangan Bulat di Kelas VII. (Tesis). Program Pascasarjana Teknologi Pembelajaran FKIP Untan Pontianak.

Trianto. (2009). Mendesain Model Pembelajaran Inovatif-Progresif : Konsep, Landasan, dan Implementasinya pada Kurikulum Tingkat Satuan Pendidikan (KTSP). Jakarta : Kencana Prenada Media Group. 